\title{
Uncertainty assessment and applicability of an inversion method for volcanic ash forecasting
}

\author{
Birthe Marie Steensen $^{1}$, Arve Kylling ${ }^{2}$, Nina Iren Kristiansen ${ }^{2}$, and Michael Schulz ${ }^{1}$ \\ ${ }^{1}$ Research department, Norwegian Meteorological Institute, Oslo, 0131, Norway \\ ${ }^{2}$ Atmosphere and Climate Department, Norwegian Institute for Air Research (NILU), Kjeller, 2007, Norway \\ Correspondence to: Birthe Marie Steensen (birthesteensen@gmail.com)
}

Received: 30 November 2016 - Discussion started: 27 January 2017

Revised: 2 June 2017 - Accepted: 9 June 2017 - Published: 31 July 2017

\begin{abstract}
Significant improvements in the way we can observe and model volcanic ash clouds have been obtained since the 2010 Eyjafjallajökull eruption. One major development has been the application of data assimilation techniques, which combine models and satellite observations such that an optimal understanding of ash clouds can be gained. Still, questions remain regarding the degree to which the forecasting capabilities are improved by inclusion of such techniques and how these improvements depend on the data input. This study explores how different satellite data and different uncertainty assumptions of the satellite and a priori emissions affect the calculated volcanic ash emission estimate, which is computed by an inversion method that couples the satellite retrievals and a priori emissions with dispersion model data. Two major ash episodes over 4 days in April and May of the 2010 Eyjafjallajökull eruption are studied. Specifically, inversion calculations are done for four different satellite data sets with different size distribution assumptions in the retrieval. A reference satellite data set is chosen, and the range between the minimum and maximum 4-day average load of hourly retrieved ash is $121 \%$ in April and $148 \%$ in May, compared to the reference. The corresponding a posteriori maximum and minimum emission sum found for these four satellite retrievals is 26 and $47 \%$ of the a posteriori reference estimate for the same two periods, respectively. Varying the assumptions made in the satellite retrieval is seen to affect the a posteriori emissions and modelled ash column loads, and modelled column loads therefore have uncertainties connected to them depending on the uncertainty in the satellite retrieval. By further exploring our uncertainty estimates connected to a priori emissions and the mass load uncertainties in the satellite data, the uncertainty in the a priori
\end{abstract}

estimate is found in this case to have an order-of-magnitudegreater impact on the a posteriori solution than the mass load uncertainties in the satellite. Part of this is explained by a too-high a priori estimate used in this study that is reduced by around half in the a posteriori reference estimate. Setting large uncertainties connected to both a priori and satellite mass load shows that they compensate each other, but the a priori uncertainty is found to be most sensitive. Because of this, an inversion-based emission estimate in a forecasting setting needs well-tested and well-considered assumptions on uncertainties for the a priori emission and satellite data. The quality of using the inversion in a forecasting environment is tested by adding gradually, with time, more observations to improve the estimated height versus time evolution of Eyjafjallajökull ash emissions. We show that the initially too-high a priori emissions are reduced effectively when using just $12 \mathrm{~h}$ of satellite observations. More satellite observations ( $>12 \mathrm{~h}$ ), in the Eyjafjallajökull case, place the volcanic injection at higher altitudes. Adding additional satellite observations ( $>36 \mathrm{~h}$ ) changes the a posteriori emissions to only a small extent for May and minimal for the April period, because the ash is dispersed and transported effectively out of the domain after 1-2 days. A best-guess emission estimate for the forecasting period was constructed by averaging the last $12 \mathrm{~h}$ of the a posteriori emission. Using this emission for a forecast simulation leads to better performance, especially compared to model simulations with no further emissions over the forecast period in the case of a continued volcanic eruption activity. Because of undetected ash in the satellite retrieval and diffusion in the model, the forecast simulations generally contain more ash than the observed fields, and the model ash is more spread out. Overall, using the a posteri- 
ori emissions in our model reduces the uncertainties in the ash plume forecast, because it corrects effectively for falsepositive satellite retrievals, temporary gaps in observations, and false a priori emissions in the window of observation.

\section{Introduction}

The fine-ash fraction (ash particles with diameter $<64 \mu \mathrm{m}$ ) of tephra from volcanic eruptions can be transported over large distances and cause jet engine malfunction and damages to airplane windshields (Casadevall, 1994). Both the 2010 April and May Eyjafjallajökull eruption and the May 2011 Grimsvötn eruption caused flight delays and cancellations leading to economical loss (European Commission, 2011). Although satellite observations can show snapshots of the instantaneous horizontal extension of ash, volcanic ash transport and dispersion models (VATDMs) are needed to forecast the dispersion of the volcanic clouds. These models need a robust estimate of source parameters such as ash release height, amount of ash released, and ash particle sizes. The combined choice of these source parameters is below named the source term. During an eruption, information about the source term is often limited. Stohl et al. (2011) present an inversion method to calculate a source term constrained by satellite observations, using a priori source terms and model simulations. This inversion technique has been successfully applied to calculate ash emissions from the Eyjafjallajökull and Grimsvötn eruptions as well the 2014 Kelut eruption (Stohl et al., 2011; Kristiansen et al., 2012, 2015; Moxnes et al., 2014). The method has also been applied to volcanic eruptions with $\mathrm{SO}_{2}$ emissions (Kristiansen et al. 2010; Eckhardt et al., 2008).

The satellite data, a priori, and model input data required by the inversion algorithm all have assumed uncertainties connected to them that weight their relative contributions to the inversion results. Both the assumed a priori and satellite uncertainties used in the studies mentioned above vary from around $100 \%$ of the input data values down to $0 \%$, or a minimum value based on the confidence of the a priori source term and satellite data available for the three eruption cases. For the Kelut eruption, however, where the eruption reached the stratosphere, the a priori source term was highly unreliable, so the uncertainty was set to $1000 \%$ of the assumed a priori values to make the result be almost exclusively driven by the satellite data. Eckhardt et al. (2008) found small differences between the a posteriori estimates when using a zero or a non-zero constant value a priori estimate for the 2007 Jebel at Tair eruption. This highlights that uncertainty settings in the inversion are case dependent. In this study, inversion calculations with different assumed uncertainties are presented to increase understanding of the effects on the a posteriori emissions.
Boichu et al. (2013) investigated the $\mathrm{SO}_{2}$ emissions of the 2010 Eyjafjallajökull eruption in early May by a similar inversion method and found that $\mathrm{SO}_{2}$ source terms calculated with only a single satellite image gave consistent results for young plumes but showed increased uncertainty as the plume evolved. A better source term for the entire episode studied may be found by assimilating several satellite observations over the entire period studied. Wilkins et al. (2016a) used an insertion method for ash forecasting by initializing a dispersion model with ash layers derived from retrievals of the Spinning Enhanced Visible and Infrared Imager (SEVIRI) on board the Meteosat Second Generation (MSG-2) satellite. The study found that the model field calculated by including up to six satellite observations gave a broader and more extensive ash cloud, which compared worse to the satellite observation on 8 May at 09:00 UTC than a single satellite retrieval inserted $6 \mathrm{~h}$ before the observation time. The ash cloud found by several retrievals is considered a more conservative choice for giving commercial air traffic advice, however, as it includes ash that may not be captured by a single observation.

In the previous studies using the inversion method by Stohl et al. (2011), the a posteriori source terms were calculated after the eruption had ceased and using all satellite data available for the entire eruption period. However, in this study more satellite observations will be added gradually to the inversion algorithm to simulate a real forecast scenario. The purpose of using the inversion method is to make the modelsimulated ash with the inversion-derived a posteriori source term more similar to the observed ash column loads than model simulations with source terms calculated by empirical plume height relationships like the one given in Mastin et al. (2009) (used here as a priori source term). The inversion algorithm only calculates a constrained source term up until the start of the forecast, as it requires satellite observations. For emissions to be used during the forecast period there are several possibilities: for example, (1) assume no further emissions, (2) use the latest a priori emission from Mastin et al. (2009), or (3) use the average of the last hours of the a posteriori from the inversion. Assuming the eruption continues, the third option includes some information from the satellite observations that may limit the uncertainty of using a priori default emission. The use of an average of the emission during the last $12 \mathrm{~h}$ will be compared here against zero emissions in the forecast period.

Meteorological clouds that contain ice, supercooled droplets, or unfrozen cloud droplets decrease the ability to identify ash in satellite retrievals or retrieve higher concentrations than what is the truth (Prata and Prata, 2012; Kylling et al., 2015). Retrieval of ash from one single satellite image of the cloud is therefore more uncertain than a series of retrievals covering a longer time period. Hourly SEVIRI satellite retrievals are used in this study, and weaknesses in the satellite retrievals are explored further by differentiating pix- 
els where no ash is detected and unclassified pixels where it is uncertain if the pixels contain ash.

The aim of this study is to use the inversion method by Stohl et al. (2011) in a forecasting setting and investigate how changes in input influence emission estimate results. Two 4-day periods in April and May of the 2010 Eyjafjallajökull eruption are studied. During the first period from 14 to 18 April, an ash cloud is transported over central Europe originating from ash emitted on 14 and 15 April, while a smaller amount is released on 17 April. The second period studied covers 5 to 9 May, when more ash was emitted again after a period with low emissions. The ash was transported south and entrained in a high-pressure system causing the ash cloud to persist over the North Atlantic and stay in the domain over the whole period. More satellite observations are therefore available for this episode.

The paper is structured as follows: Sect. 2 gives a short description of the inversion method; the model and satellite data used in this study; and the structure, amplitude, and location (SAL) scoring method (Wernli et al., 2008), a performance metric that also was used in Wilkins et al. (2016a). Results are presented in Sect. 3: first the sensitivity of inversion calculations to input data uncertainty is demonstrated; secondly, the robustness of the calculated source term is tested by simulating a real case, where increasing amounts of satellite data are used, and modelled ash clouds are compared to observed ones. Discussion and conclusions are given in Sects. 4 and 5, respectively.

\section{Methods}

\subsection{Source estimate calculations}

Assimilated volcanic source terms are calculated in this study by an inversion algorithm, based on the work given in Seibert (2000), and further developed to calculate the vertical distribution of volcanic emissions by Eckhardt et al. (2008) and Kristiansen et al. (2010). Stohl et al. (2011) present modifications to the method to also produce time-resolved emission estimates of ash for the 2010 Eyjafjallajökull eruption. Since the inversion method for volcanic ash source terms has been extensively described in previous studies, further detailed description of the inversion method will not be given here, but some aspects are presented for the use in a forecasting setup.

The algorithm calculates an assimilated source term using input data from a dispersion model and satellite retrievals, as well as a priori emission estimates. First, source receptor model data, representing all possible dispersion scenarios of the ash cloud, are matched with satellite data. For each grid point in the considered domain, modelled column loadings over every hour of the assimilation time that exceed a certain threshold (here $10^{-12} \mathrm{~g} \mathrm{~m}^{-2}$ ) resulting from a unit ash emission $\left(1 \mathrm{~kg} \mathrm{~s}^{-1} \mathrm{~m}^{-1}\right)$ released from one particular emission time and height are matched with the corresponding as- similation time and grid point of the satellite ash mass loading retrieval. Using a threshold exceedance criterion for the model data helps reduce the data volume and inversion CPU time. Model source receptor calculations are done by using an unit emission that are later scaled by the a priori emissions in the algorithm, making it possible to change the a priori estimate without performing new model calculations. Model simulations used for the inversion are further described in Sect. 2.2. Since grid boxes are used only where model results have ash loads above the threshold, the chance of the result being influenced by possible false-positive ash retrievals in the satellite data, described in Sect. 2.3, is reduced. On the other side, grid points which are unclassified, meaning it is uncertain whether they contain ash or not, are excluded from the inversion calculations. To reduce the amount of data and computational time, a randomly selected $70 \%$ of the gridded data points, which hold satellite data with definitely no ash, are discarded, similar to Stohl et al. (2011).

\subsection{Model simulations}

Volcanic ash dispersion calculations are done with the EMEP (European Monitoring and Evaluation Programme) MSCW (Meteorological Synthesizing Centre - West) model described in Simpson et al. (2012); updates are in addition presented in the yearly EMEP reports (EMEP MSC-W, 2016). Model modifications to improve the description of ash dispersion, such as gravitational settling in all model layers, are described in Steensen et al. (2017). This new version of the model is called the emergency EMEP (eEMEP) model. Simulations are done with 3-hourly meteorological input from the ECMWF (European Centre for Medium-Range Weather Forecasts) IFS (Integrated Forecasting System) model with a horizontal resolution of $0.25 \times 0.25^{\circ}$ in latitude and longitude, with 42 layers in the vertical. The model domain spans from 40 to $80^{\circ} \mathrm{N}$ and $40^{\circ} \mathrm{W}$ to $30^{\circ} \mathrm{E}$. The ash emissions are distributed over nine ash particle size bins from 4 to $25 \mu \mathrm{m}$ particle diameter with an ash density of $2500 \mathrm{~kg} \mathrm{~m}^{-3}$.

To produce source receptor model input for the inversion calculations, a unit amount of ash is released from 19 height intervals above the volcano as a pulse over a period of $3 \mathrm{~h}$. The 3-hourly ash emissions are distributed over the appropriate model layers given by the height intervals in the source emissions. Simulations are started every $3 \mathrm{~h}$ until the whole period of interest is covered. With the current setup, ash is assumed to have a maximum residence time in the domain of 6 days before it is transported out of the domain or settled to the ground. The simulations therefore last for 6 days after the pulse emission is released.

There are uncertainties connected to the model simulation caused by uncertainties in the meteorological input and assumptions about ash in the model. Stohl et al. (2011) tested the sensitivity of different model ash size distributions to the inversion calculations and found that, as the satellite observations only see a small range of ash size classes, changing the 


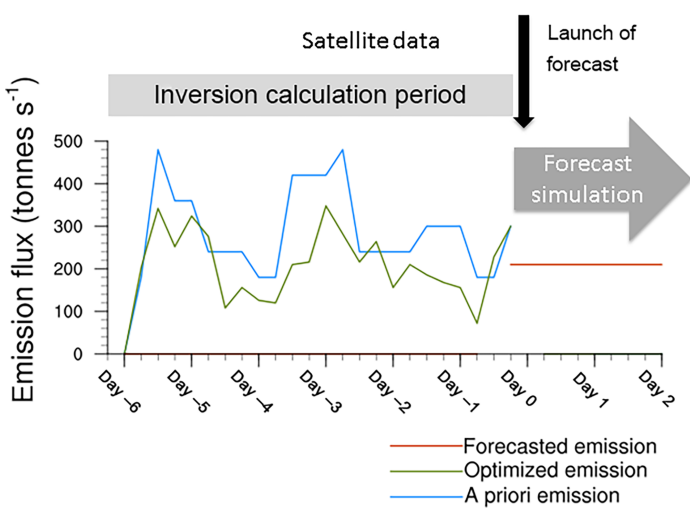

Figure 1. Scheme of how the evolution of ash emissions used in the eEMEP model simulations may look, with an a priori emission estimate, the calculated a posterior (optimized) emission estimate, and a forecast emission estimate.

distribution over the size bins gave a negligible difference. The model simulations used as input to the inversion are also done for an early part of the forecasted meteorological data when numerical weather prediction model uncertainties are still small. Errors caused by uncertainty in the meteorology and modelled size distribution are assumed minimal in our setup, compared to the uncertainties connected to a priori emissions, and satellite data and will not be studied here.

Figure 1 shows the timeline of the inversion calculation and the forecast via the eEMEP model simulation, both as used in this study and in the case of a real volcanic eruption. The a posteriori source term calculated from the inversion routine is used as the emission source term in the model simulations and can reach back up to 6 days counted from the forecast start time. An emission estimate for the forecast period is normally calculated as the average of the last $12 \mathrm{~h}$ of the a posteriori source term. For practical reasons, the two model simulations (inversion method and forecast) are run separately from each other.

\subsection{Satellite data}

Ash satellite detection and retrievals are made using infrared measurements by SEVIRI on board the MSG-2 satellite. MSG-2 is geostationary, centred at approximately $0^{\circ}$ latitude, and has a $70^{\circ}$ view coverage (Schmetz et al., 2002). Pixel resolution is $3 \times 3 \mathrm{~km}$ at nadir, while at the edge of the coverage it increases to $10 \times 10 \mathrm{~km}$. Observations are available every $15 \mathrm{~min}$. Pixels are identified as containing ash if the brightness temperature difference (BTD) between the SEVIRI 10.8 and $12.0 \mu \mathrm{m}$ channels (Prata, 1989) is below a certain threshold value, here $-0.5 \mathrm{~K}$. The BTDs have been adjusted for water vapour absorption using the approach of Yu et al. (2002). Ash clouds give negative BTDs, ice give positive BTDs, and BTDs of water clouds are closer to zero.

For the inversion, satellite observations for every hour are used as input and forward interpolated to the $0.25 \times 0.25^{\circ}$ model domain; if two or more pixels belong to the same grid cell, the column loads are averaged. Two examples for April and May are shown in Fig. 2. Grey areas in the plots represent unclassified pixels where the satellite ash detection cannot determine if ash is present or not; that is, the BTD is around zero, and pixels can therefore contain water, ice, and ash. The ash detection can falsely classify ash in regions where there is no ash over land due to spectral land surface emissivity and for pixels with large viewing angles close to the edge of the SEVIRI coverage (Prata and Prata, 2012). For the first date shown at the beginning of the eruption (15 April 2010 at 12:00 UTC, left plot in Fig. 2), stationary ash clouds are detected both to the north and west of Iceland, while the main ash emission is transported east towards Norway, indicating that these ash clouds to the north and west are likely false positives. Other false positives are observed over Great Britain and in the North Atlantic Ocean for this time. For the second retrieval shown (7 May at 12:00 UTC, right plot in Fig. 2), a large ash cloud is detected to the southwest of Iceland that probably does not originate from volcanic emissions according to our understanding of the transport conditions. Because of the different thresholds and method used to detect ash, this cloud is not detected in the Francis et al. (2012) and Wilkins et al. (2016a) studies. False positives may be included in the inversion calculation because in a forecasting environment manual adjustments to the satellite data for these pixels can be difficult to accomplish; however, since model data where no ash is transported are disregarded, the chances of false positives being used in the inversion calculations are minimal.

The ash mass loading and effective ash particle radius are retrieved as described in Kylling et al. (2015). The retrieval is based on a modification of the Bayesian optimal estimation technique used by Francis et al. (2012). There are several factors that affect the ash retrieval, causing uncertainties in the calculated column loadings. Corradini et al. (2008) studied uncertainties due to $\pm 2 \mathrm{~K}$ surface temperature and $\pm 2 \%$ surface emissivity changes and found total mass retrieval errors of 30 and $10 \%$, respectively. The same study also estimated a retrieval error of $10 \%$ caused by variations in ash plume altitude and cloud thickness, and shows an almost approximately proportional uncertainty retrieval error due to water vapour. Changing the ash type (e.g. from andesite to the ash type from Volz, 1973) also give uncertainties in the total mass (Corradini et al., 2008; Francis et al., 2012; Wen and Rose, 1994). Wen and Rose (1994) studied the volcanic eruption at Crater Peak, Alaska, in 1992 and found that total mass is doubled due to changes in ash particle size distribution. Kylling et al. (2014) found a $30 \%$ difference in total mass due to the assumed ash particle shape. The effect of meteorological clouds is seen to both increase and decrease the retrieved ash mass loading (Kylling et al., 2015).

We assume andesite ash with refractive index from Pollack et al. (1973), spherical ash particles, and a lognormal size distribution. The lognormal size distribution is described by the 

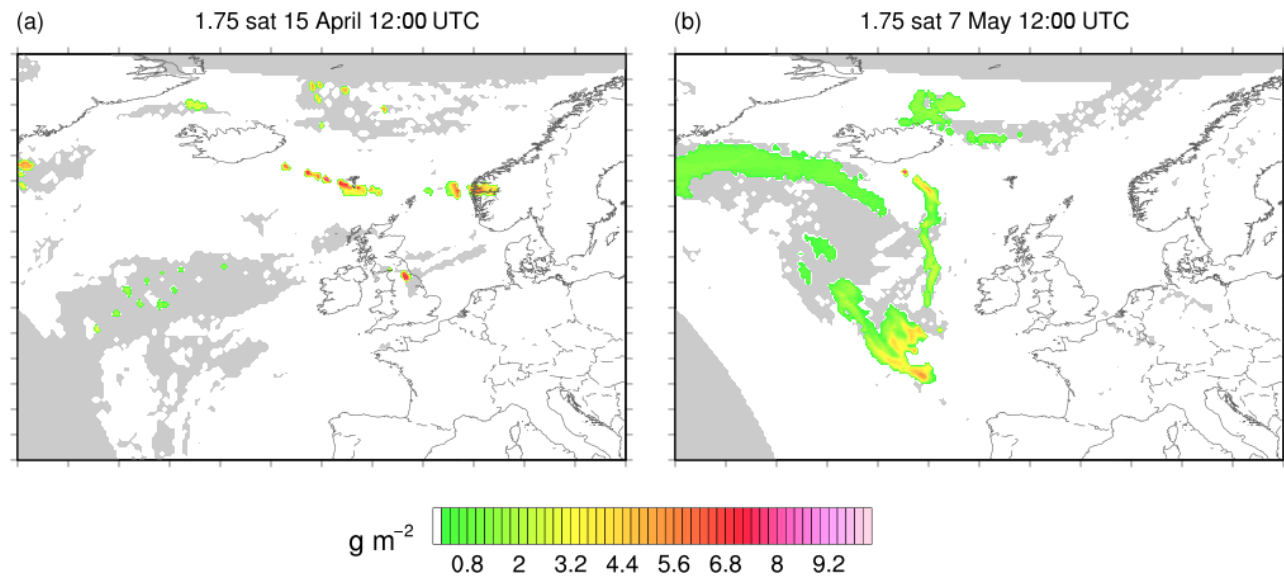

Figure 2. (a) and (b) SEVIRI satellite ash mass loading with a 1.75 lognormal size distribution on 15 April 2010 at 12:00 UTC and on 7 May 2010 at 12:00 UTC. The grey areas show the unidentified pixels, where the ash retrieval cannot distinguish whether or not there is ash.

geometric mean radius and the geometric standard deviation. The geometric mean radius is related to the effective radius which is retrieved. To test the sensitivity to the shape of the size distribution, the geometric standard deviation was varied between $1.5,1.75,2.0$, and 2.25 , which is a subset of the values used by Francis et al. (2012). The four satellite retrievals with different geometric standard deviations are henceforth referenced as sat 1.5 , sat 1.75 , sat 2.0 , and sat 2.25 . Figure 3 shows the total ash mass in the domain for every hour during the Eyjafjallajökull eruption from the four satellite data sets. A larger geometric standard deviation gives a wider size distribution that includes more of the larger ash particles and therefore increased retrieved ash mass loading. The difference between the four satellite sets (Fig. 3) shows the effect the size distribution shape has on the observed ash loads. For the inversion algorithm an additional uncertainty is assigned to the ash loads in the grid cell. To see the effect of the mass loading uncertainties on the inversion calculations, four uncertainties are assigned to the satellite data in separate inversion calculations: $0,50,100$, and $200 \%$ of the retrieved column load in each grid cell.

\subsection{A priori emissions}

Mastin et al. (2009) present an empirical relationship between observed height and mass emission rate (MER) based on historic volcanic emissions.

$\operatorname{MER}=\left(\frac{H}{2.0}\right)^{-0.241} \times \rho$

The observed plume heights $(H)$ used in this study are given in Arason et al. (2011) with a $3 \mathrm{~h}$ temporal resolution; density $(\rho)$ for ash is the same as in the model simulations $\left(2500 \mathrm{~kg} \mathrm{~m}^{-3}\right)$. A priori MER over the eruption period is shown in Fig. 3. The a priori emission is distributed uniformly over the total emission column. Mastin et al. (2009) also gave a fine-ash fraction for classified volcanoes over the globe based on previous eruptions. Larger tephra is assumed to fall close to the volcano, and this tephra-associated fraction of the total MER is not available for long-range transport and is not included in our simulations. Large tephra is also not observed by the infrared satellite instruments using the BTD technique. The fine-ash fraction for the Eyjafjallajökull volcano, classified as a silicic standard case, is 0.4, which is higher than the 0.1 fine-ash fraction used in Stohl et al. (2011) and Kristiansen et al. (2012). However, 0.4 is chosen to simulate a real-case forecasting mode, where this fraction must be assumed as it is likely to be the only information available in the first phase of an emergency. Note this higher fraction involves significantly higher a priori emissions than used by Stohl et al. (2011) and Kristiansen et al. (2012). Note also that the observed heights used to calculate the a priori emissions here are on some occasions lower than the more uncertain heights used in the previous mentioned studies as the Arason et al. (2011) heights were not available at the time of these studies. Since a rather conservative a priori method is used here that does not favour any release height over another, the uncertainty range, within which the a priori estimate may fall, is chosen to be for four test cases 25, 50, 75, and $100 \%$. We assume that this is informative to understand how uncertainty in the a priori emitted mass is weighted in the inversion calculations.

\subsection{SAL metric}

To measure the performance of the model as more observations are added to the inversion algorithm for the source term calculations as well as its forecast ability, the SAL scores (Wernli et al., 2008) are computed and evaluated. The SAL method is an object-based quality measure originally developed to evaluate quantitative precipitation forecast with observations and later applied to air quality forecasts (Dacre et al., 2011). The satellite data used for the inversion are also used for calculating the SAL scores. One advantage is the 


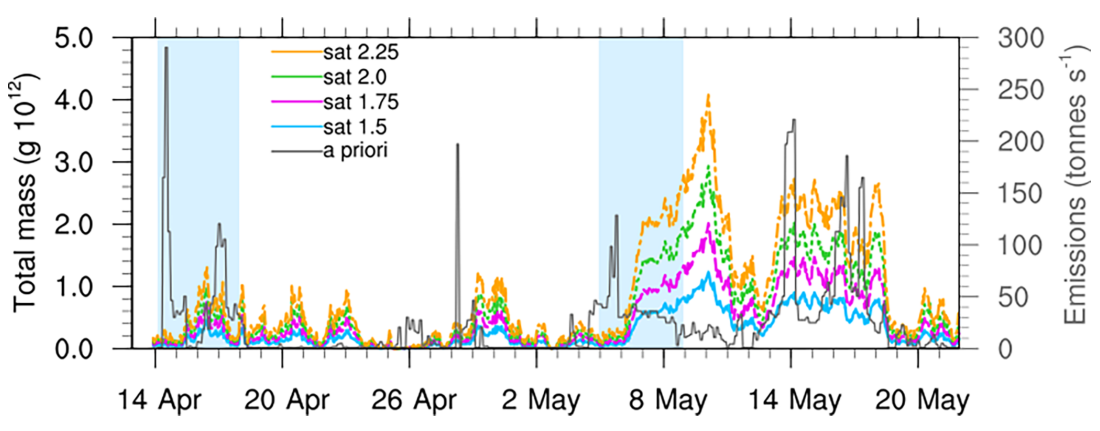

Figure 3. Left axis shows the total mass of ash in the domain for the four satellite retrievals with different size distribution assumptions (sat 1.5-2.25), for every hour over the entire Eyjafjallajökull eruption period. Right axis shows the emissions in the a priori estimate calculated from observed plume height at the volcano. The blue shaded areas indicate the periods studied in the paper.

broad spatial coverage of the satellite data. While this does not allow a totally independent check of the assimilation, it provides information on how much the different amounts of satellite data entering the inversion procedure influence the performance in the observed period and in the forecast period. In particular in the forecast period, the satellite data are rather independent from the inversion. Objects are identified in the forecast and observations field where parameter values exceed a certain threshold. The equations used to calculate the $S, A$, and $L$ components of the method are described in Wernli et al. (2008) and Wilkins et al. (2016a); only a short description will be given here.

As in Wilkins et al. (2016a) a more conservative ash threshold value of $0.5 \mathrm{~g} \mathrm{~m}^{-2}$ is chosen to identify objects for the satellite and model fields, even though the satellite detection threshold is considered to be about $0.2 \mathrm{~g} \mathrm{~m}^{-2}$ (Prata and Prata, 2012).

For the amplitude component, the average ash mass over the domain is calculated for the modelled and observed fields. $A$ is the normalized difference between these two averages and ranges from -2 to +2 , with 0 being the perfect forecast. An $A$ value of +1 indicates a model overestimation by a factor of 3 , and values of 0.4 and 0.67 represent model overestimations of 1.5 and 2 , respectively.

The structure component compares the normalized volume objects by scaling the ash loading with the maximum ash loading within each object. Forecast and observed objects are then weighted proportionally to the ash mass of the objects. $S$ is the normalized difference between these weighted modelled and observed volumes. $S$ also ranges from -2 to +2 . $S$ is positive when the model ash field is too spread out and flat, while a negative value correspond to a model field that is peaked and/or too small.

The first part of the $L$ component measures the normalized distance between the centres of mass for the modelled and observed fields. Different ash clouds can have the same centre of mass, and the second part of $L$ considers the averaged distance between the centre of mass of the total field and individual objects. Both parts of $L$ range between 0 and
1; the maximum of $L$ is +2 . The definition of $L$ is, however, insensitive to the rotation around the centre.

The combined SAL score is given by $(|S|+|A|+L)$, a perfect forecast is given by 0 , and the maximum score is 6 . The possibility of a perfect score forecast for modelled fields with a posteriori emissions and satellite retrievals is minimal because of the difficulties detecting ash in the satellite data; however, the tendencies of a possible improvement in the forecast can be analysed by the use of this method.

The SAL scores are calculated for every 12:00 and 00:00 UTC time step after the start of the eruption in the April and May period for the entire forecast and assimilation period. Two $48 \mathrm{~h}$ forecast experiments are characterized, one with the average emission estimate and one with zero emissions included in the forecast period. To only compare the ash clouds that are in areas where the model calculations show ash levels above a (very low) threshold value (see above), false positives in the satellite data are not included. In addition areas with unclassified pixels in the satellite data are excluded for both the observed and modelled fields.

\section{Results}

\subsection{Source term uncertainties}

Multiple inversion calculations are performed using the four satellite data sets with the different size distribution shape (sat 1.5, sat 1.75, sat 2.0, and sat 2.25) in combination with varying the uncertainties connected to the a priori source term $(25,50,75$, and $100 \%)$ and mass load satellite retrieval uncertainty due to other factors than size distribution $(0,50$, 100 , and $200 \%$.). Figure 4 shows the a priori emission estimate over time during the two periods in April and May, as well as the total range in the a posteriori emission resulting from the multiple inversion calculations. As the amount of ash emitted in the a priori emissions is a function of the observed emission height at the volcano, more ash reflects a higher observed emission column. All our a posteriori source terms reduce the emissions from the a priori estimate, sug- 


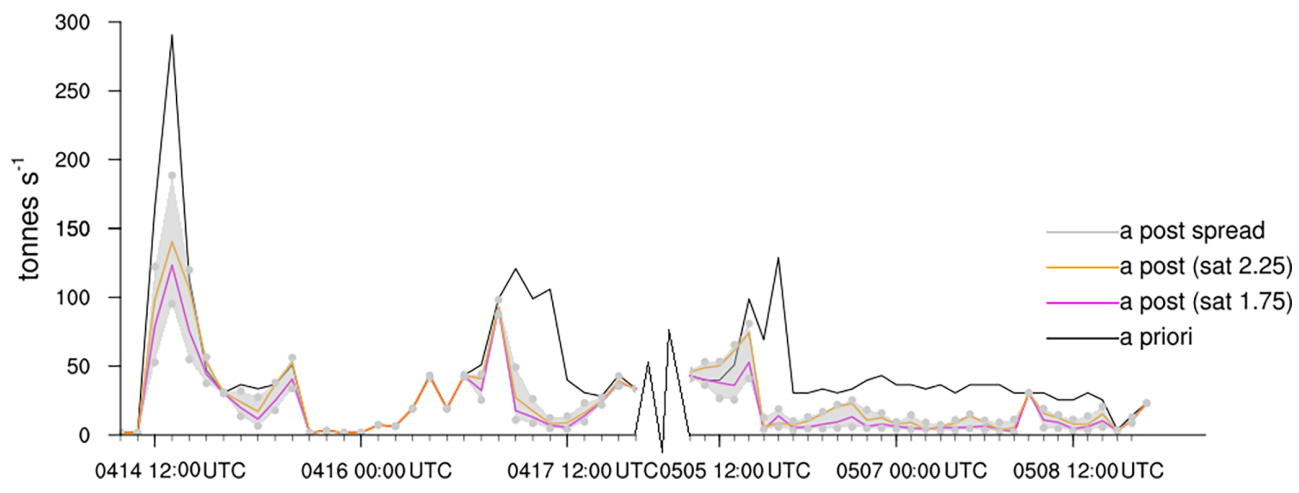

Figure 4. A priori ash emissions and the spread of a posteriori ash emissions calculated by the inversion algorithm using the different uncertainties and satellite data sets during the April and May periods (the break on the $x$ axis indicates the change in time periods). Magenta and orange lines are a posteriori emissions calculated from inversions assuming a priori uncertainty of $75 \%$ and satellite uncertainty set at $100 \%$, using a spread in ash distribution of 1.75 and 2.25 in the satellite retrieval.

gesting that the default parameter value for the fine-ash fraction of 0.4, as taken from Mastin et al. (2009), is indeed too high as discussed in Sect. 2.4. Other parameters, such as density and plume height, may also result in too much a priori emission.

In April, a high emission column at the start of the period is followed by reduced column height observations before more ash is emitted again from 16 April at 09:00 UTC. The a posteriori show a large range of solutions for the first plume released. During the low-emission period in April all the a posteriori follow the a priori as the inversion cannot constrain the a posteriori solution without any satellite observations. On 17 April, when the satellite detected more ash, the a posteriori source terms are strongly reduced compared to the a priori, similar to what is found in previous inversion studies using model input data from FLEXPART and NAME (Stohl et al., 2011; Kristiansen et al., 2012). The May period also starts with a high a priori emission, followed by a period with almost constantly lower a priori emissions. The a posteriori source term is strongly reduced for the whole period.

Figure 5 shows the average vertical distribution in the emissions over the April period for the a priori and all inversions performed, grouped into eight ensembles. In Fig. 5a the a priori uncertainty is set to $75 \%$, and for each of the four different satellite data sets the mass loading uncertainty of the satellite data is varied from 0 to $200 \%$, giving the shown spread in the vertical emission distribution estimate. In Fig. $5 b$ the mass loading satellite data uncertainty is set to $100 \%$, and the a priori emission uncertainty is varied from 25 to $100 \%$ for each of the four satellite sets. The resulting spread in vertical emission distribution for the different satellite data sets represents the a priori uncertainties studied here.

All a posteriori source terms are strongly reduced compared to the a priori, especially at altitudes below $4 \mathrm{~km}$. The reduction of ash in the resulting source term is proportional to the reduction in amount of ash in the satellite retrievals. The a posteriori solution for the satellite data set with most ash (sat 2.25) has higher emissions than the other satellite data sets with less ash. As the mass loading satellite uncertainty is a percentage of the retrieved ash for each grid point, the satellite set with the highest column loads also shows the largest spread (Fig. 5a). When comparing Fig. 5a and b, however, one finds this spread to be much smaller than that caused by varying the a priori uncertainty (Fig. 5b). Similar spread results are found for calculations with a smaller 0.1 fine-ash fraction (not shown here).

Another feature can be found in these plots of the vertical distribution of the emissions and the spread at different heights. Since the inversion redistributes ash emissions to the heights where transport processes the best match to satellite observations, the vertical distribution is changed from a priori. The emission close to the ground is reduced, and the largest spread due to a priori uncertainty is at this altitude (below $4 \mathrm{~km}$ ) (Fig. 5b). More trust in the a priori source term (low uncertainty) causes the a posteriori source term to deviate less from the a priori profile (right part of the result envelopes in Fig. 5b). The leftmost profile representing the lowest emission term is attained with high uncertainty for the a priori emissions and little ash mass retrieved by the satellite (sat 1.5). Therefore the a posteriori source terms for this satellite data set have the largest spread as a function of variation in a priori uncertainty. The corresponding vertical emission distribution plots for the May period show similar results (not shown).

The spread in a posteriori source terms caused by varying the inversion input, with regards to both the column loads in the satellite retrieval and uncertainties connected to them, and the a priori emission uncertainty represent the ambiguity in the a posteriori. Ideally, uncertainties should be set at values that are representative of the real uncertainties connected to the data; however, these uncertainties are often not well known at the start of an eruption. Using a range of uncertainty values is probably not feasible in an operational set- 

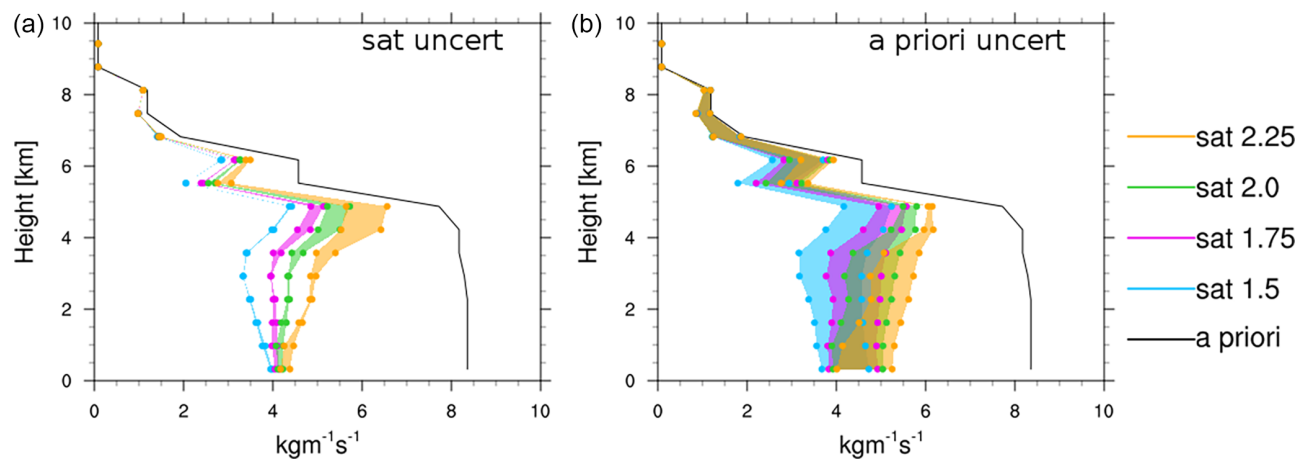

Figure 5. Spread of a posteriori for the four satellite data sets with the four different size distribution assumptions (sat 1.5-2.25). (a) shows the spread in a posteriori caused by varying the uncertainty connected to the satellite data, with a priori uncertainty set at $75 \%$. (b) shows the spread in a posteriori caused by varying a priori uncertainty, with a constant satellite uncertainty at $100 \%$.

ting. But the results presented here provide insight into the impact of the uncertainties on the resulting spread of the a posteriori source term. It may guide operational efforts in the case of future volcanic eruptions to establish a combination of realistic uncertainty estimates, not being unnecessarily over-precise on individual uncertainties.

For the remainder of the results presented in this study, a column load satellite uncertainty of $100 \%$ and an a priori uncertainty of $75 \%$ will be used on the 1.75 satellite retrieval data that are termed "the reference a posteriori", shown as a magenta line in Fig. 4. The inversion result and associated simulation are our best guess and a reference for comparing our different experiments. Table 1 shows for instance that the total emitted fine ash for the a priori source term is reduced by around $45 \%$ for April and $65 \%$ for May in the reference a posteriori seen against the a priori source term. The different ranges of the total a posteriori ash emission for the different satellite retrievals, the mass load satellite uncertainties, and the a priori uncertainties are also calculated by fixing the other two parameters as the reference. For both periods, the largest spread is caused by the four different satellite retrievals, while changing the mass load satellite uncertainty produces the smallest spread in this case. Since this smaller spread is seen to depend on the amount of ash in the satellite retrieval, forecast simulations are therefore also done for the 2.25 satellite retrieval with the same uncertainty estimates as for the reference (orange line in Fig. 4).

\subsection{Inversion in forecasting mode}

In a real volcanic alert case, more and more information will become available while the event is enfolding. To test and investigate the change in the a posteriori source term as more observations become available, new inversion calculations are made every $12 \mathrm{~h}$ of the 4-day periods in April and May. The first inversion calculations become available at 00:00 UTC on 15 April and 00:00 UTC on 6 May with observations accumulated up until that time $(24 \mathrm{~h}$ of satellite observations). It would have been possible to do the first in- version calculations before this first time step; the satellite observations often have problems detecting the ash close to Iceland due to the high optical thickness of the ash cloud close to the volcano, so only a few satellite observations are available. Figures 6 and 7 show the a priori as well as a subset of the consecutive a posteriori vertical distribution emission estimates at 3-hourly resolution, calculated with observations that would have been available up until 00:00 UTC for each day of interest in April and May. Comparing multiple consecutive estimates illustrates how robust the a posteriori emission is, especially for the first high ash emissions in the periods.

The first a posteriori source term calculated with satellite data up until 15 April at 00:00 UTC shows a strong reduction in the emissions compared to the a priori over the emission columns from 09:00 to 18:00 UTC on 14 April (Fig. 6). Adding another $24 \mathrm{~h}$ of satellite observations increases the emissions at $8 \mathrm{~km}$ height, while reducing the emissions closer to the ground. This redistribution is caused by the transport patterns seen in the satellite ash images, which imply that transport happened at high altitudes and not at low altitudes. Even more observations including days 3 and 4 only change the 14-15 April emission estimate slightly. Figure 4 shows that the a posteriori estimates have minimal differences compared to the a priori between 15 April at 12:00 UTC and 17 April at 00:00 UTC. The larger impact of the inversion on emission estimates altering the a priori to rather low values for the second part of the emissions on 17 April is caused by there being only a few hours of satellite observations.

Figure 7 shows that the high emission estimates during the first $24 \mathrm{~h}$ of the May period overall are also reduced early on in the first inversion result. The first $9 \mathrm{~h}$ show agreement between a priori and a posteriori. For the 15:00-21:00 UTC period on 5 May, there are numerous height levels where emissions are zero. This is caused by how the inversion algorithm handles unphysical negative inversion calculations that are caused by inaccuracies in model and data. The standard error for these negative source vector elements are reduced, and in- 
Table 1. Total fine-ash emissions in Tg over the April and May period for the a priori estimate and the reference a posteriori with the satellite retrieval with 1.75 geometric standard deviation, $100 \%$ uncertainty in the satellite data, and $75 \%$ uncertainty of the a priori emission. Below are shown the minimum and maximum a posteriori results by only changing the satellite retrieval, satellite mass load uncertainty, and a priori uncertainty while keeping the other uncertainties at reference levels. The spread between maximum and minimum is also given as a percentage of the reference.

\begin{tabular}{|c|c|c|c|c|}
\hline & Apr & May & $\begin{array}{r}\% \text { of } \\
\text { reference } \\
\text { Apr }\end{array}$ & $\begin{array}{r}\% \text { of } \\
\text { reference } \\
\text { May }\end{array}$ \\
\hline A priori & 17.4 & 13.3 & & \\
\hline Reference a posteriori & 9.5 & 4.7 & & \\
\hline Sat. ret. $(\min / \max )$ & $9.4 / 11.0$ & $4.2 / 6.4$ & $26 \%$ & $47 \%$ \\
\hline Sat. uncert. $(\min / \max )$ & $9.4 / 9.5$ & $4.7 / 4.8$ & $1 \%$ & $2 \%$ \\
\hline A pri. uncert. (min/max) & $9.0 / 11.4$ & $4.7 / 5.8$ & $25 \%$ & $23 \%$ \\
\hline
\end{tabular}
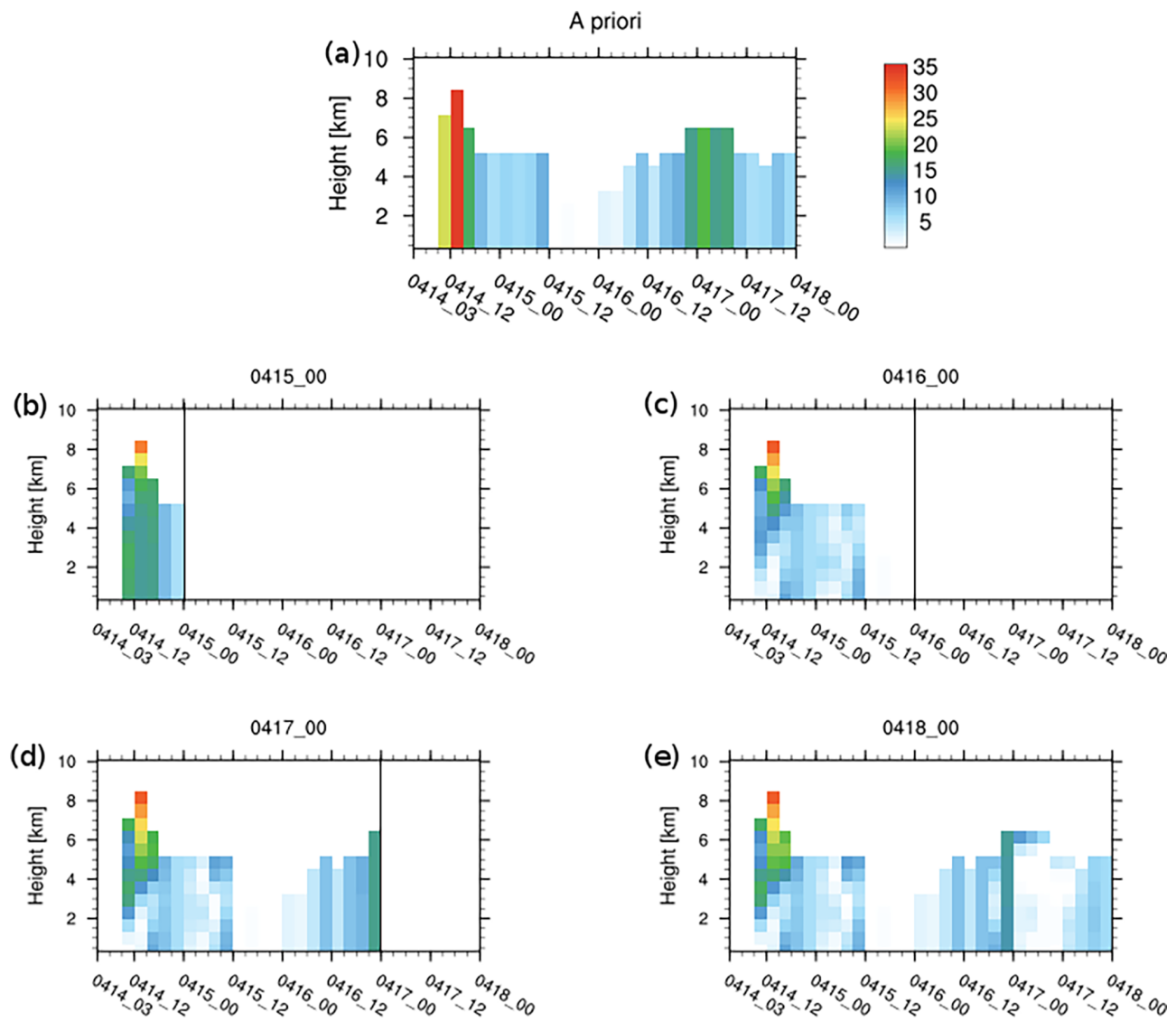

Figure 6. Vertical emission distributions over the volcano with $3 \mathrm{~h}$ resolution, given in $\mathrm{kg} \mathrm{m}^{-1} \mathrm{~s}^{-1}$. A priori source term (a) and a posteriori source terms (b-e) by using satellite observations up until the start of the forecast time (vertical black line) over the April period. Only the a posteriori term for the 00:00 UTC forecasts are shown.

version calculations are repeated until the sum of all negative emissions is less than $1 \%$ of the sum of positive emissions (Eckhardt et al., 2008). Small negative emissions that are still present in the estimate are set to zero. By adding more observations, these artefacts are reduced, and the negative values are replaced by very low emissions, indicating a more confident estimate. Another noticeable factor is the number of observations needed to reduce the emission released between 21:00 UTC on 6 May and 00:00 UTC on 7 May. The first estimate calculated on 8 May at 00:00 UTC shows little reduction; only when more observations up to 8 May at 12:00 UTC are included (not shown, but visible in the inversion on 9 May at 00:00 UTC) do these emissions become small. Similar difficulties in correcting the night-time emission are seen for 


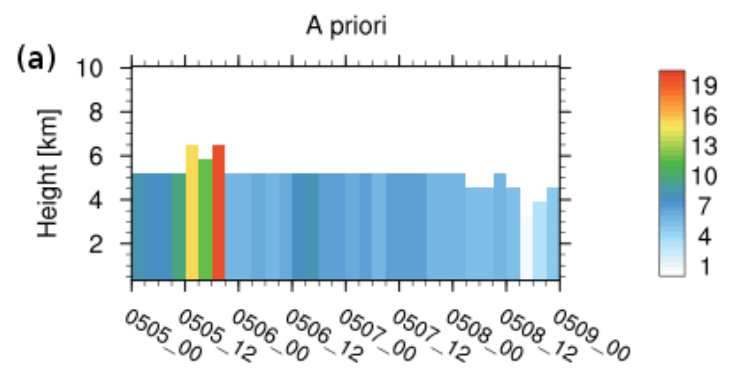

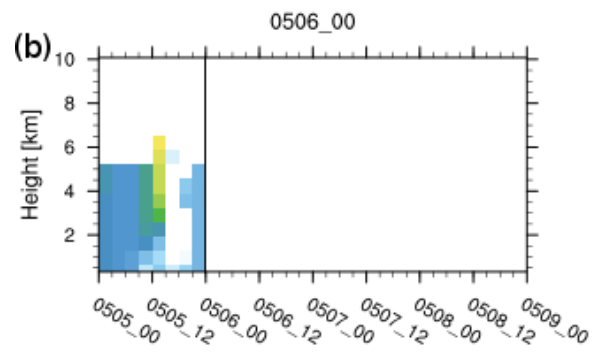

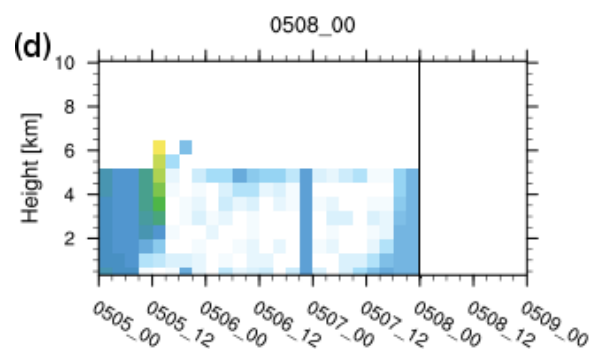

Figure 7. Same as Fig. 6 but for the May period.

the emission from 21:00 UTC on 7 May to 00:00 UTC on 8 May as well as during the April period. The reason for this is beyond the scope of this study; however, the results indicate that there is an increased uncertainty connected to the inversion method attempting to derive night-time emissions.

Figure 8 shows where the differences in vertical emission distribution are located when two satellite data sets are fed into the inversion calculation for the two periods. Although more ash in the satellite retrieval sat 2.25 causes the source emission to have higher emission fluxes, the change in a posteriori emissions when adding more observations is similar for the 1.75 and 2.25 satellite retrievals for both the April and May periods. Although the biggest differences are seen for the same emission time as the maximum flux of the emission estimate during the two periods, the largest differences are closer to the ground. The increase of the maximum emission fluxes at the higher levels between the two satellite retrieval is minimal. During April, the highest emission level is transported quickly out of the domain, while lower levels are transported over Europe with larger differences between the satellite retrievals. For the May period, the large difference below $4 \mathrm{~km}$ are caused by the satellite retrieval in sat 2.25 having an increase over time in column loading for the southerly part of the plume that is not present in the sat 1.75 .
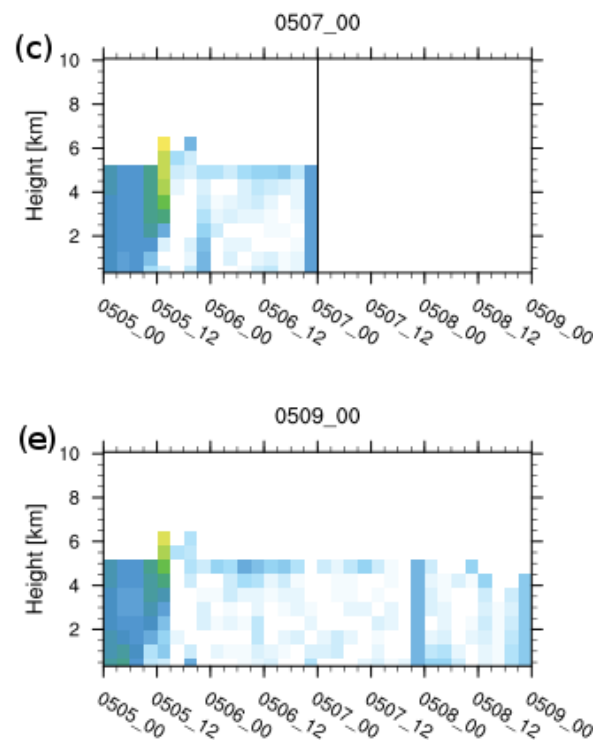

This different increase in ash loading over time between the different satellite retrievals is because the size distribution enters the radiative transfer equation non-linearly. The emissions released at higher levels have been transported further north and are not affected by this.

\subsection{Forecast model results compared to satellite observations}

Figure 9 show the ash distribution satellite retrievals (sat 1.75) every $12 \mathrm{~h}$ from 16 April at 12:00 UTC to 17 April at 12:00 UTC. It also shows corresponding model results for a simulation with an a posteriori source term calculated up to the satellite observation and corresponding results including a $36 \mathrm{~h}$ forecast period, applying a mean forecasted emission term established for the $12 \mathrm{~h}$ preceding the start of the forecast. All the model results have more extensive ash clouds than were observed. Maximum concentrations are, however, high in the observed data $\left(10.5 \mathrm{~g} \mathrm{~m}^{-2}, 9.5\right.$, and $6 \mathrm{~g} \mathrm{~m}^{-2}$ on 16 April at 12:00 UTC, 17 April at 00:00 UTC, and 17 April at 12:00 UTC, respectively). Disregarding areas close to the volcano, Fig. 9b shows that initially simulated ash concentrations, right after the assimilation period, have the highest concentrations of ash in the area of observed ash, but with a 

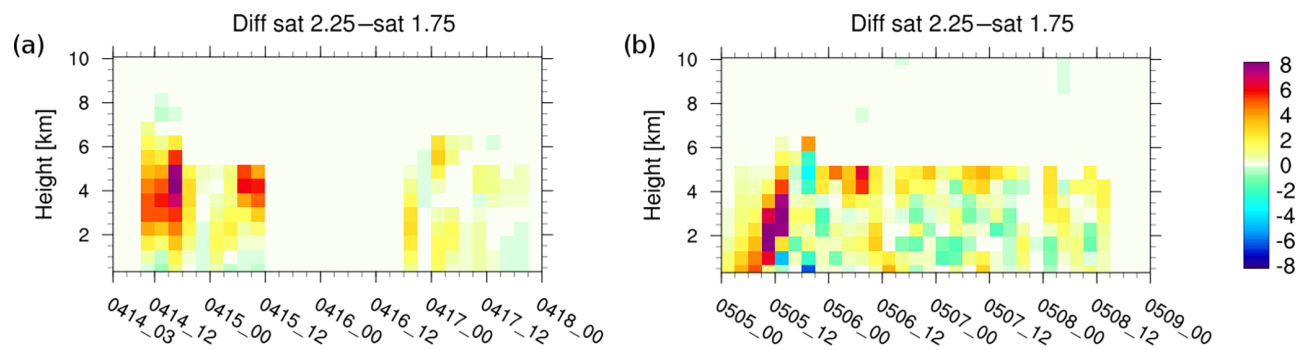

Figure 8. The difference in emissions $\left(\mathrm{kg} \mathrm{m}^{-1} \mathrm{~s}^{-1}\right)$ between the a posteriori source terms for the inversions using the 2.25 and 1.75 satellite data sets over the two periods in April (a) and May (b).

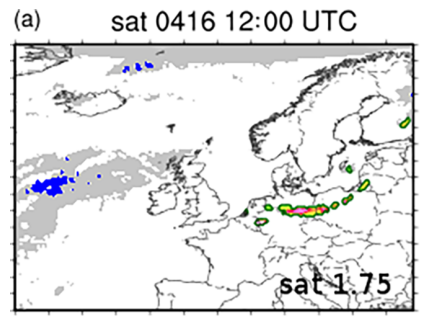

(d)

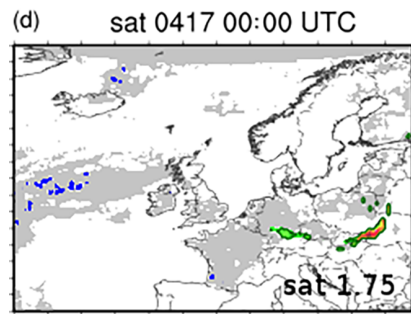

(g)

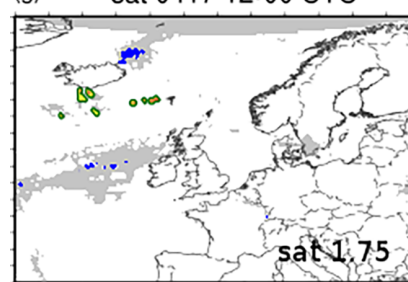

(b) $\bmod 041612: 00$ UTC +0

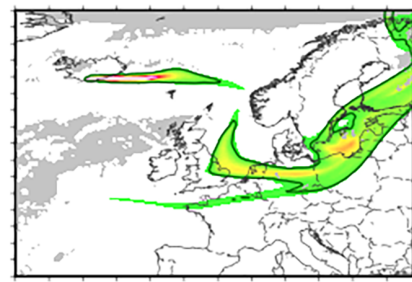

(e) $\bmod 041700: 00$ UTC +0

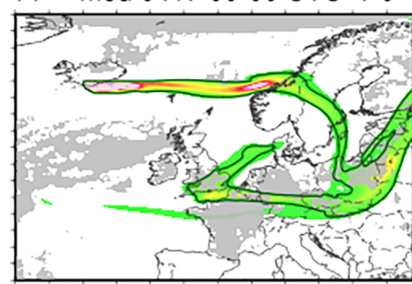

(h) $\bmod 041712: 00$ UTC +0

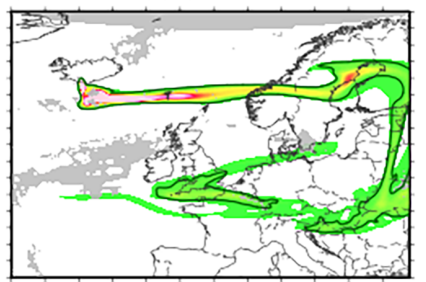

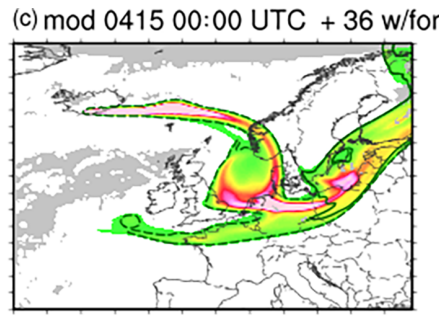

(f) $\bmod 041512: 00$ UTC $+36 \mathrm{w} / \mathrm{for}$

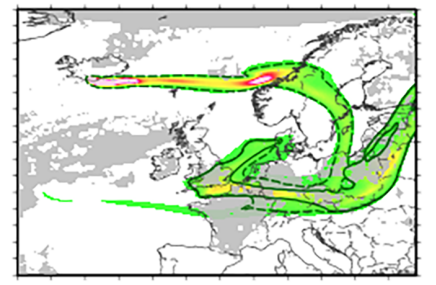

(i) $\bmod 041600: 00$ UTC $+36 \mathrm{w} /$ for

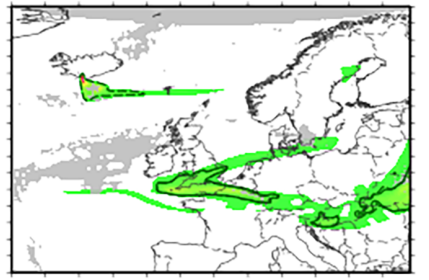

$\mathrm{g} \mathrm{m}^{-2}$

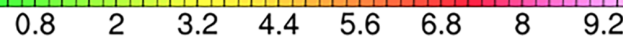

Figure 9. (a, d, g) SEVIRI satellite retrievals assuming the sat 1.75 size distribution on 16 April at 12:00 UTC (a), 17 April at 00:00 UTC (d), and 17 April at 12:00 UTC (g). Blue areas indicate where the satellite has false-positive detection of ash. (b, e, h) show model simulations with a posteriori emissions calculated from the inversion assuming the 1.75 size distribution, using all satellite retrievals up until the time indicated above the figure (same as satellite). (c, f, i) show model forecasts for the same time as the two first columns but with a posteriori emissions calculated with satellite observations up to $36 \mathrm{~h}$ before and a forecast emissions term for the remaining $36 \mathrm{~h}$. The green line encircles objects used for SAL (structure, amplitude, and location) scoring, where ash exceeds the $0.5 \mathrm{~g} \mathrm{~m}^{-2}$ limit for model and observed ash. Ash released in the forecast term is shown with a dashed line (only the rightmost column).

maximum of $5.1 \mathrm{~g} \mathrm{~m}^{-2}$ the modelled ash column values are lower compared than the maximum values in the observations. The forecast started using the first emission estimate, covering emissions released before 15 April at 00:00 UTC (Fig. 9c); have high a posteriori emissions and therefore also high forecast emissions, causing a large amount of ash to be released into the atmosphere; and have maximum column load of $19.5 \mathrm{~g} \mathrm{~m}^{-2}$ in the area where the satellite retrieve ash.
The model simulation does not manage to transport narrow ash clouds with high concentrations due to numerical diffusion, and the initially simulated concentrations (Fig. 9b) therefore have smaller maximum values. For the next forecasts starting $12 \mathrm{~h}$ later (Fig. 9f), the emissions are already reduced. Differences between the forecast starting on 17 April at 00:00 UTC (Fig. 9e) and the $36 \mathrm{~h}$ forecast (Fig. 9f) are minimal due to low emissions during this time; both have maxi- 


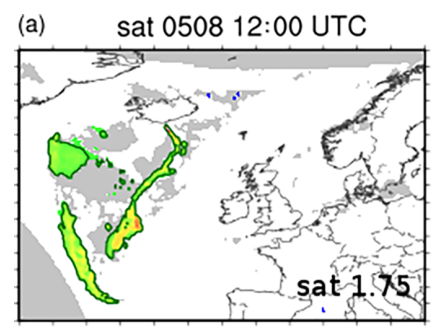

(d) sat 0508 12:00 UTC

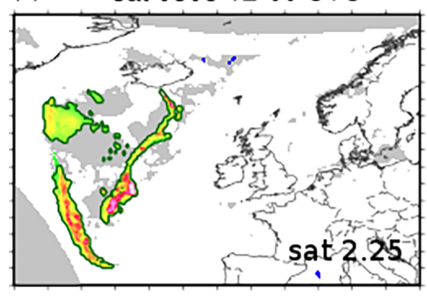

(b) $\bmod 0508$ 12:00 UTC + 0

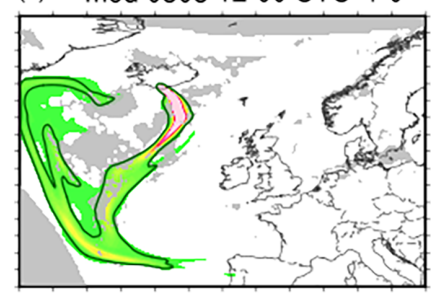

(e) $\bmod 050812: 00$ UTC + 0
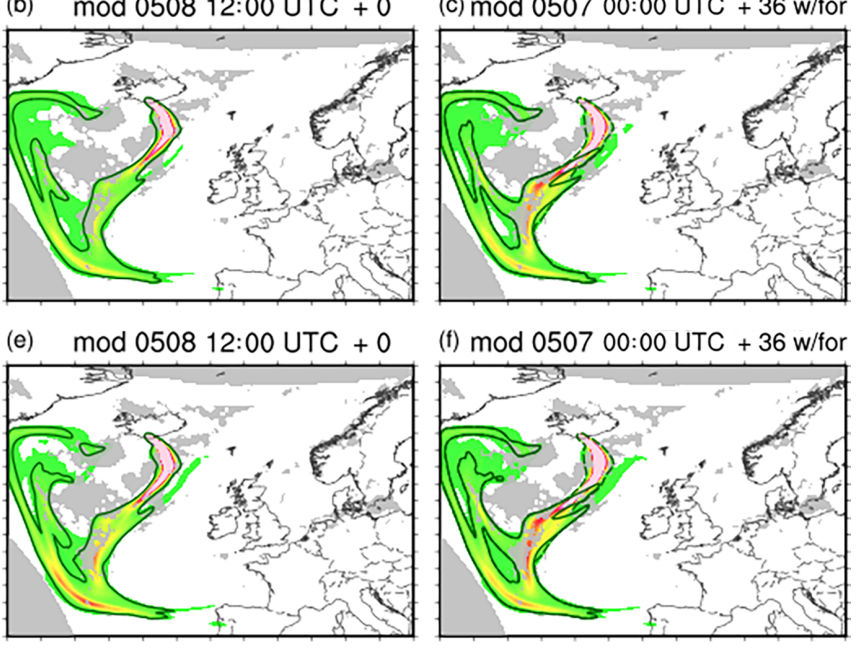

$\mathrm{g} \mathrm{m}^{-2}$

0.8
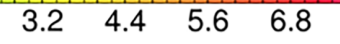

$\begin{array}{ll}8 & 9.2\end{array}$

Figure 10. The same as Fig. 9 but for 8 May at 12:00 UTC, showing the satellite data (a, d) and a posteriori model simulations for the first forecast hour (b, e) and $36 \mathrm{~h}$ forecasts $(\mathbf{c}, \mathbf{f})$ with inversions for satellite retrieval data with the $1.75(\mathbf{a}, \mathbf{b}, \mathbf{c})$ and 2.25 (d, e, f) size distribution assumption.

mums over central Europe at 4.0 and $5.1 \mathrm{~g} \mathrm{~m}^{-2}$ for the initial simulation and forecast, respectively. In both model simulations there is an area with higher column loads to the south of Iceland due to more emissions being accumulated by weak northerly winds. No ash is retrieved in the satellite observation. For the satellite plot in Fig. 9g retrieved $12 \mathrm{~h}$ later, ash is detected to the east of Iceland that had been released before $12 \mathrm{~h}$ prior, demonstrating the difficulty of retrieving the opaque ash clouds close to Iceland. For this retrieval, there is also no ash detected over Europe, even though ash was observed over Europe at this time (Pappalardo et al., 2013).

The exemplary results in Fig. 9 show that for a $36 \mathrm{~h}$ forecast, i.e. a long forecast including an unknown emission estimate, rapid changes in the mass eruption rate may lead to significant error.

While the ash observations during the April episode are characterized by small observed ash clouds with high ash concentrations, the observations of the ash during the May period show larger ash clouds with lower column loadings. Figure 10a and $\mathrm{b}$ show retrieved satellite ash on 8 May at 12:00 UTC for the 1.75 and 2.25 size distributions. Model results with a posteriori source term calculated with the satellite retrievals up to 8 May at 12:00 UTC and a $36 \mathrm{~h}$ forecast from 7 May at 00:00 UTC are also shown. Because of small ash emission estimated from 6 May at 00:00 UTC onwards, the differences between the forecast emission estimate and the assimilated estimate is minor, except for more ash south of Iceland for both satellite retrievals for the initial simulation. As discussed in the previous section, for the most southerly ash cloud in the 2.25 satellite retrieval the ash column loads increase over time and cause the cloud in the model results in Fig. 10e to have more ash than in the forecast simulation (Fig. 10f) even though this emission is already inverted from previous observations of the ash cloud. This change in the emission estimate for distant, early emissions caused by more satellite observations demonstrates the ability to improve ash simulations when ash has been obscured by clouds in earlier retrievals.

\subsection{Performance quantification forecasts}

The SAL score and its components (see Sect. 2.5) are calculated every $12 \mathrm{~h}$ during the simulation periods including the assimilation period plus a $48 \mathrm{~h}$ forecast to quantify the performance of the model as more and more observations are added. SAL scores are also calculated for a simulation using the a priori estimate to estimate how the assimilated source term improves over the a priori.

For the April period, the retrieved satellite ash clouds are small compared to model clouds and consequently the $S$ and $A$ scores become very high. An exception is for the retrieval on 17 April at 00:00 UTC, where the areas with unclassified retrievals are large over Europe (Fig. 9d). This large unidentified area is due to high emissivity over land during nighttime that disrupts the brightness temperature retrieval quality. Removal of these areas in the model data causes the fields to be more comparable. Even though the model ash clouds are indeed larger and more spread out than the observed ash for the period, comparing the observed and modelled fields for this time provides some information about how the amount of ash is changed by adding more observations. Table 2 shows the SAL scores for the two satellite retrievals (sat 1.75 and sat 2.25) and the corresponding model stimulations with the emission estimates constrained by the satellite 
(a)

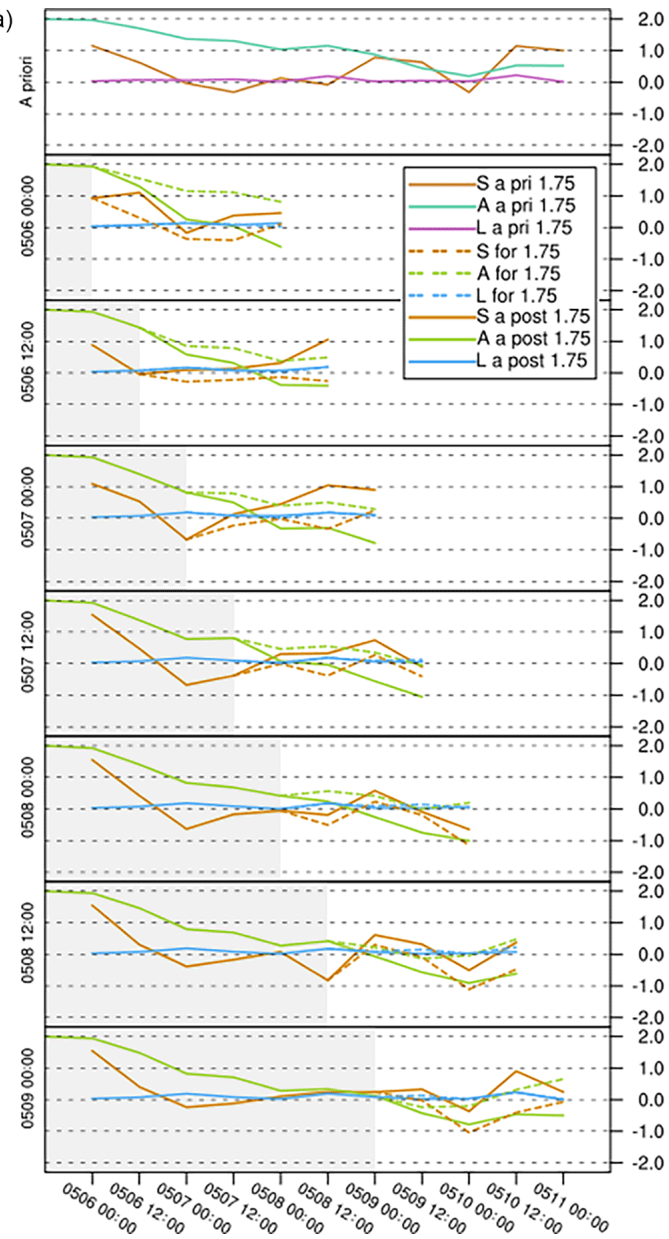

(b)

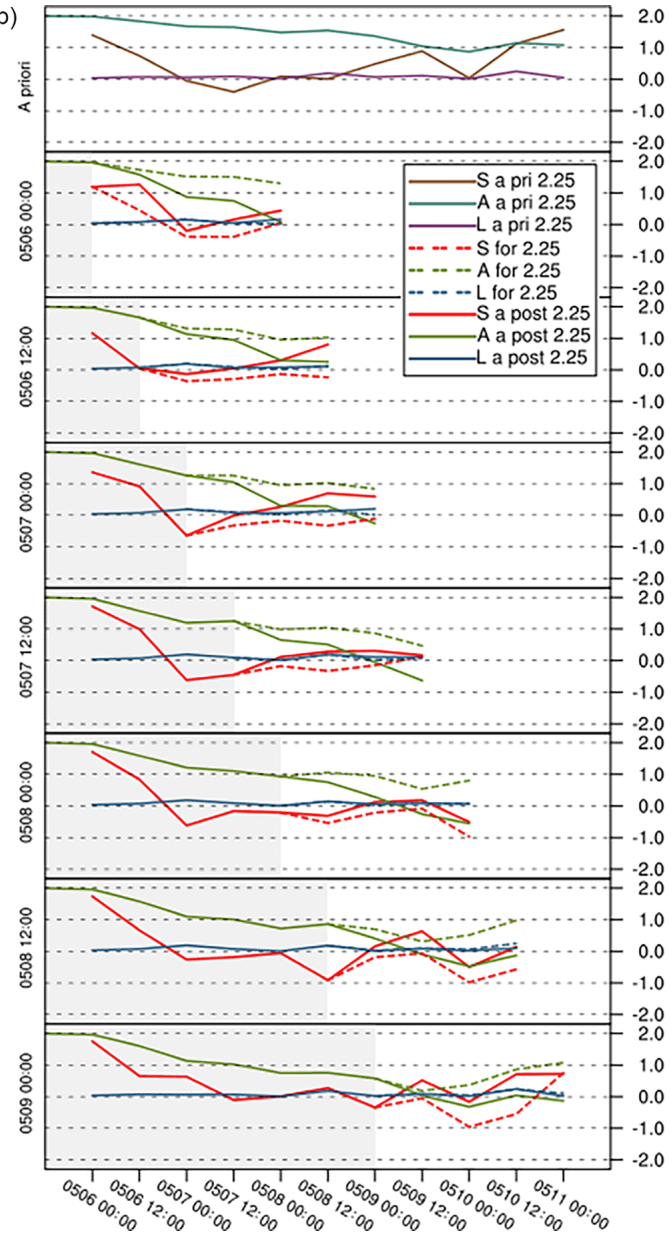

Figure 11. SAL (structure, amplitude, and location) results for model simulations run with the a priori emissions calculated for the 1.75 (a) and 2.25 (b) satellite retrieval (top row), and results for the model simulations using a posteriori emissions started every $12 \mathrm{~h}$ from 6 May at 00:00 UTC to 9 May at 00:00 UTC with a $48 \mathrm{~h}$ forecast using either a forecast emission estimate (dashed lines) or a zero ash emission term in the forecast (straight lines). Grey areas show the assimilation period where the emission estimate is calculated by the inversion. Model simulations with the 1.75 a posteriori source term are compared to the 1.75 satellite observation field, and those with the 2.25 a posteriori emissions are compared to 2.25 satellite retrievals. Date format: MMDD; e.g. "0506" stands for 6 May.

retrievals. For the simulations where the assimilation period and inversion estimate end before the comparison time (15 April at 00:00 UTC to 16 April at 12:00 UTC) the $12 \mathrm{~h}$ averaged forecast emission estimate is added, while for the rest of the model simulations (17 April at 00:00 UTC to 18 April at 00:00 UTC) the observation is included in the assimilation calculations. Compared to the a priori estimate, all forecast model results are worse for the structure $(S)$ component because of the too-spread-out model fields. The amplitude $(A)$ scores that measure the amount of ash in the domain are, however, improved for the second assimilation with forecast estimate (15 April at 12:00 UTC $+36 \mathrm{~h}$ ) and the preceding simulations. The structure score does not improve until the satellite observation from 17 April at 00:00 UTC is included in the assimilation (three lasts lines in Table 2). This improvement is due to a smaller area over the 0.5 threshold over Europe in these simulations.
Figure 11 shows all the SAL scores in the May period for satellite observations and the model simulations for the sat 1.75 (a) and the sat 2.25 (b) size assumptions. SAL score calculations are in addition done for a $48 \mathrm{~h}$ forecast with the last $12 \mathrm{~h}$ average emission estimate (dashed lines) and zero emission (solid lines) over the forecast period. Because of the optically thick ash cloud close to the volcano, there is no ash originating from the Eyjafjallajökull eruption in the satellite retrieval from 5 May at 12:00 UTC, it is not possible to calculate the location $(L)$ and structure $(S)$ scores for these times, and the amplitude $(A)$ gives the worst score (2) due to infinitely more model ash than in the satellite data. SAL scores generally are better during the May period because of the increase in both the area with retrieved ash and the total amount of ash for the observation field compared to the April period. The first emissions in the May a posteriori estimate are not reduced enough in the inversion calculations, 
Table 2. Structure, amplitude, and location (SAL) scores (ranging from -2 to 2 for structure and amplitude, and 0 to 2 for location; best is 0 for all) for different model simulations for comparison on 17 April at 00:00 UTC using satellite retrievals (sat 1.75 and sat 2.25; see text). The model simulations that end the assimilation window before the comparison, and then use assumed forecast emission are marked as + hh hours. The last three lines correspond to simulations where the forecast starts after the observation comparison time.

\begin{tabular}{|c|c|c|c|c|c|c|}
\hline \multirow[t]{2}{*}{ Model forecast } & \multicolumn{2}{|c|}{ Structure } & \multicolumn{2}{|c|}{ Amplitude } & \multicolumn{2}{|c|}{ Location } \\
\hline & sat 1.75 & sat 2.25 & sat 1.75 & sat 2.25 & sat 1.75 & sat 2.25 \\
\hline A priori & 0.20 & 0.37 & 1.82 & 1.69 & 0.26 & 0.22 \\
\hline \multicolumn{7}{|c|}{ Forecast starting before 17 April at 00:00 UTC } \\
\hline $15 \mathrm{Apr}$ at 00:00 UTC $+48 \mathrm{~h}$ & 0.92 & 1.05 & 1.90 & 1.83 & 0.18 & 0.13 \\
\hline $15 \mathrm{Apr}$ at $12: 00 \mathrm{UTC}+36 \mathrm{~h}$ & 0.57 & 0.77 & 1.75 & 1.62 & 0.20 & 0.16 \\
\hline $16 \mathrm{Apr}$ at 00:00 UTC $+24 \mathrm{~h}$ & 1.00 & 1.23 & 1.21 & 0.91 & 0.32 & 0.25 \\
\hline 16 Apr at $12: 00 \mathrm{UTC}+12 \mathrm{~h}$ & 0.36 & 0.75 & 1.66 & 1.47 & 0.24 & 0.22 \\
\hline \multicolumn{7}{|c|}{ Simulations with observation included in the assimilation to the inversions } \\
\hline 17 Apr at 00:00 UTC & -0.21 & 0.32 & 1.79 & 1.66 & 0.23 & 0.21 \\
\hline 17 Apr at 12:00 UTC & -0.18 & 0.35 & 1.78 & 1.65 & 0.23 & 0.21 \\
\hline 18 Feb at 00:00 UTC & -0.15 & 0.42 & 1.78 & 1.65 & 0.24 & 0.21 \\
\hline
\end{tabular}

causing the $A$ score to be high for the comparison of 6 May at 00:00 UTC in all the model comparisons. Transport later in the period aligns this model ash released early with ash released later in the period, forming the southern ash cloud (Fig. 10). For the comparison time of 7 May at 00:00 UTC, the two forecast estimates show good results for the $S$ score, while the model simulations with this observation time late in the assimilation period perform worse. Further into the period as the observation time becomes earlier in the assimilation period, the model performs better for both $A$ and $S$. The two model simulations with an assimilation period up to 9 May at 00:00 UTC score better for the $A$ and $S$ than all the other model simulations for most of the comparison times, even though the emission estimate did not change much during this time.

The $A$ and $S$ scores are positive for most comparison times, showing that the model fields have more ash and that the fields are more spread out than the satellite observations. This can be explained by the difficulty of retrieving ash close to the volcano and by ash that is obscured by meteorological clouds.

The ash location score $(L)$ between satellite and model data is low, both because the centres of mass are close to each other in the domain and because the $L$ score for the idealized fields shown in Wernli et al. (2008) is lower than the $S$ and $A$ values. Low $L$ values also indicate that the transport of ash in the model compares well to observations, which also indicate that the ash emissions are placed in the right layer.

Although the a posteriori source terms are calculated by using different satellite retrievals and compared to their respective satellite data, the scores for the two satellite data sets do not show large differences. The difference in the $S$ score on 17 April at 00:00 UTC is caused by less ash in the small objects for the 1.75 observed fields. For the May period, the
$S$ scores are similar to each other; however, more ash in the 2.25 satellite retrievals compares better to the amount of ash in the model simulations, leading to a better $A$ score for the 2.25 satellite retrievals.

\section{Discussion}

Emission fluxes in the a posteriori source terms depend on the amount of ash in the satellite retrieval and the weighting of uncertainties connected to the input data to the inversion. Giving the a priori a high uncertainty causes the a posteriori source term to deviate from the a priori, while assigning a high uncertainty to the satellite data forces an inversion solution closer to the a priori source term. It is therefore important that the a priori and satellite uncertainties connected to these values represent reasonable assumptions. Default settings for an operational setup can ignore some aspects of a volcanic eruption for the size distribution and amount of tephra in emissions.

Of major importance is the uncertainty in the satellite data input to the inversion, and especially the change in ash loads by using different assumptions about the shape of the ash size distribution. The results in this study show that the spread in a posteriori estimates due to mass load satellite uncertainties is much smaller than the spread when using the four different satellite sets with different size distributions. For the a posteriori source term it is therefore important to use the best available assumptions in the satellite retrieval rather than correct mass load uncertainty assumptions.

Satellite retrievals from other satellites instruments with better spatial resolution - such as MODIS (ModerateResolution Imaging Spectroradiometer), IASI (Infrared Atmospheric Sounding Interferometer), and VIIRS (Visible Infrared Imaging Radiometer Suite) - may provide more con- 
fidence in the extent of the ash clouds (Clarisse et al., 2010). Such retrievals may carry similar uncertainty for finding ash mass but may bring additional size information and separation of ash from cloud. Satellite information can also give information about the height of the ash layer. This may be obtained from dual-view instruments such as SLSTR (Sea and Land Surface Temperature Radiometer), and space-borne lidars such as CALIOP (Cloud-Aerosol Lidar with Orthogonal Polarization) also provide valuable information if their narrow footprint matches the ash cloud (Winker et al., 2012).

The SEVIRI satellite observations have high temporal resolution as a new retrieval is available every $15 \mathrm{~min}$ for the whole domain. Polar-orbiting satellites, on the other hand, may only observe a small part of the domain during an overpass. Stohl et al. (2011) show that performing inversion with only IASI retrievals may provide a too-small sampling size to constrain the solution. Ash mass loadings from other satellite retrievals with better aerosol detection capability are nevertheless useful for comparisons with the amount of ash in the SEVIRI retrieval and a possible combination of the satellite retrievals with the SEVIRI retrieval for the inversion.

The a posteriori is found to only use the a priori estimate in the absence of ash in the satellite retrievals; this solution is independent of the uncertainty settings for a priori and satellite data. A good a priori estimate is therefore important for these cases. Observed heights from Arason et al. (2011) obtained by weather radars are used in this study, and the heights show a good match with the maximum a posteriori heights. However, the fine-ash fraction is found to be too large, causing too much ash to be released during the April period compared to the satellite retrievals. Observations and more information are needed to produce a good a priori estimate. At the time of the Eyjafjallajökull eruption, Iceland had only one operational weather radar to observe the plume height, situated at Keflavik International Airport, $155 \mathrm{~km}$ to the west of the volcano (Arason et al., 2011). Another permanent weather radar is now situated in the eastern part of Iceland, and two mobile radars are prepared (Jordan et al., 2013). Monitoring of activity on Iceland is also improved by the FUTUREVOLC project (http://futurevolc.hi.is) and will increase the amount of observations available in the case of future volcanic eruption.

Even when higher a priori emission heights are used for the estimate for the Eyjafjallajökull eruption as in Stohl et al. (2011) and Kristiansen et al. (2012), their results show that the inversion algorithm places ash at heights equal to those found in this study. The fine-ash fraction of 0.1 used in Stohl et al. (2011) and Kristiansen et al. (2012) gives, however, a better match than the too-high 0.4 used in this study for the periods where the satellite observations are too few to constrain the a posteriori (and the a posteriori solution therefore only uses the a priori estimate). Even though the 0.1 fine-ash fraction matches better with satellite retrievals, Gudmundsson et al. (2012) found by studying ash deposition on land almost 4 times more very fine ash $(<28 \mu \mathrm{m})$ for the first days of the Eyjafjallajökull eruption (14-16 April) than Stohl et al. (2011) a posteriori ash emissions for the entire eruption. This large discrepancy indicates that satellite observations indeed do not observe all ash that is either obscured by meteorological clouds or ash clouds that are too opaque.

Eckhardt et al. (2008) showed that a posteriori calculated with no emission in the a priori emission gave similar results to a posteriori calculated with estimated emissions in the a priori. A posteriori estimates are also calculated with low ash emissions in the a priori estimates in the Moxnes et al. (2014) and Kristiansen et al. (2015) studies. An a priori emission with ash is considered more conservative due to undetected ash. A parallel sensitivity calculation with no or little ash in the a priori estimation is possible in the case of a volcanic eruption but was not done in this study.

The insertion method presented in Wilkins et al. (2016a) and a refined method in Wilkins et al. (2016b) only take into account the ash in the satellite retrievals and add no additional emissions from the volcano in the forecast, eliminating the concerns with the a priori emissions for periods with no ash detected. By inserting several ash retrievals in the model field several times, possible undetected ash can be included in the calculations as it may become visible in later satellite retrievals. Comparing the insertion and the inversion methods for 16 April 2010 at 12:00 UTC shows that the insertion method have ash clouds only at similar location to the observations, while the results presented here have too-extensive ash clouds. Wilkins et al. (2016a) also present SAL metric results from 8 May 2010 at 09:00 UTC. Although not calculated at the same satellite retrieval time, the SAL metric results in this study for May are better for a long forecast period. The amplitude score for the insertion method shows that the averaged mass in the model results is less than retrieved ash, while in this study model simulations have more ash than in the retrieval. Some of these differences are caused by the inversion calculations using only the a priori estimate in the absence of satellite observations, for the April period, and how the observation fields are defined for the SAL score calculations. In Wilkins et al. (2016a) the observed satellite data are represented by the maximum values retrieved over the previous hour, while in this study the observations are strictly the ash loading retrieved at the time studied. Another reason is the difficulty that the satellite retrievals have detecting high-density ash close to the volcano, leading to both too much ash in this study, which includes these ash clouds in the forecast, and possibly too little ash in the insertion method, which does not use emissions over the forecast period.

\section{Summary and conclusions}

In this paper an inversion method for source term calculations is tested in an operational forecasting setup over two short periods of 4 days during the Eyjafjallajökull eruption. Both of these periods started with high ash emissions during 
the first day; while the observations of ash during the April period indicated small clouds with high column loadings, the retrieved ash clouds during the May periods were larger in extent with lower column loads. This provides an opportunity to explore the feasibility of using an inversion method to constrain emission in an operational setting where the impact of volcanic eruptions on air traffic shall be assessed. The observed ash cloud during the April period is shown to be difficult to simulate in the model due to diffusion, and the model results with the a posteriori therefore have ash clouds that are more spread out and ash column loads that are lower than in satellite observations. The ash clouds observed in the May period are better simulated by the model.

A posteriori emission estimates are calculated with the inversion algorithm for four different satellite data sets with different spread in size assumptions that affect the retrieved ash column loadings. Note that the satellite data also contain areas with unclassified pixels where the satellite retrieval is not able to distinguish whether ash is present or not. These areas are ignored by the inversion algorithm. The effect of different uncertainties connected to the input satellite data and a priori estimate in the inversion is studied, and multiple inversion calculations are documented. Because of the high fine-ash fraction (0.4) assumed for Eyjafjallajökull as a silicic standard volcano (Mastin et al., 2009), the a priori estimate has too-high emissions compared to satellite retrievals, and all the calculated a posteriori source terms are reduced by the inversion. The spread in a posteriori solutions due to the a priori uncertainty for the four satellite retrievals is largest where the a posteriori and a priori estimates deviate the most. Mass loading uncertainties connected to the satellite retrieval are found to have a lower effect.

As the inversion routine forces the source term and the model simulations to be more similar to the observed ash values, ultimately better-quality data are needed for the retrieved column load values. Combining and comparing the SEVIRI satellite data with ash retrieval from other satellite instruments with different spatial and temporal resolution and different viewing angles are therefore necessary.

In a forecasting mode, the change in a posteriori estimates by adding more observations every $12 \mathrm{~h}$ shows that, although the a priori emissions are too high, they are reduced early on with only a small amount of satellite observations. Adding more observations at later times of the ash cloud, further away from Iceland, causes the inversion to redistribute the ash emissions to higher altitudes in the Eyjafjallajökull case. The redistribution is caused by ash originating from these upper-level emission heights which is found to match better with the location of the observed ash. The results show that the change in a posteriori by adding more observations is minimal after 36 to $48 \mathrm{~h}$, in particular for those times where high ash emission occurs. Emission at times with no significant ash emissions is reduced after only a few satellite observations; exceptions are found for the night-time emission estimate between 21:00 and 00:00 UTC. During the April pe- riod, large ash emissions were followed by a period of no or insignificant ash emissions, where no ash is detected in the satellite retrieval. As the a posteriori estimate uses only the a priori for emission times that are not matched with satellite observations, more information about the source term is necessary. For future Icelandic volcanic emissions such information will be available due to the increase in radar coverage in Iceland since the Eyjafjallajökull eruption.

The SAL scores show that model results at most times have more ash that is more spread out than the observations. Discrepancies between the observations and model results are explained by too much ash in the a priori and by undetected ash in the satellite retrieval close to the volcano or obscured by meteorological clouds. Model results with a posteriori emissions decrease the ambiguity when using both the forecast and the satellite observations by obtaining model ash loads more comparable to satellite values, and facilitating the interpretation of the satellite data by identifying areas with, for instance, false positives or undetected ash.

Data availability. Model code is described in Steensen et al. (2017) and is available for download (https://github.com/metno/emep-ctm/ releases/tag/rv4_10_eEMEP_ASH); SAL calculations are done using the SpatialVx package for R (https://cran.r-project.org/web/ packages/SpatialVx/index.html).

Competing interests. The authors declare that they have no conflict of interest.

Acknowledgements. The work done for this paper is funded by the Norwegian ash project financed by the Norwegian Ministry of Transport and Communications and Avinor. Model and support are also provided through the Cooperative Programme for Monitoring and Evaluation of the Long-range Transmission of Air Pollutants in Europe (no. ECE/ENV/2001/003). This work has also received support from the Research Council of Norway (Programme for Supercomputing) through CPU time granted at the supercomputers at NTNU in Trondheim.

Edited by: Thomas von Clarmann

Reviewed by: Roger Denlinger and one anonymous referee

\section{References}

Arason, P., Petersen, G. N., and Bjornsson, H.: Plumetop altitude time-series during 2010 volcanic eruption of Eyjafjallajökull, Icelandic Meteorological Office, Reykjavik, https://doi.org/10.1594/PANGAEA.760690, 2011.

Boichu, M., Menut, L., Khvorostyanov, D., Clarisse, L., Clerbaux, C., Turquety, S., and Coheur, P.-F.: Inverting for volcanic $\mathrm{SO}_{2}$ flux at high temporal resolution using spaceborne plume imagery and chemistry-transport modelling: the 2010 Eyjafjalla- 
jökull eruption case study, Atmos. Chem. Phys., 13, 8569-8584, https://doi.org/10.5194/acp-13-8569-2013, 2013.

Casadevall, T.: The 1989-1990 eruption of Redoubt Volcano, Alaska: Impacts on aircraft operations, J. Volcanol. Geoth. Res., 62, 301-316, https://doi.org/10.1016/0377-0273(94)90038-8, 1994.

Clarisse, L., Prata, F., Lacour, J. L., Hurtmans, D., Clerbaux, C., and Coheur, P. F.: A correlation method for volcanic ash detection using hyperspectral infrared measurements, Geophys. Res. Lett., 37, https://doi.org/10.1029/2010GL044828, 2010.

Corradini, S., Spinette, C., Carboni, E., Tirelli, C., Buongiorno, M. F., Pugnaghi, S., and Gangale, G.: Mt. Etna tropospheric ash retrieval and sensitivity analysis using Moderate Resolution Imaging Spectroradiometer Measurements, J. Appl. Remote Sens., 2, 023550, https://doi.org/10.1117/1.3046674 674, 2008.

Dacre, H. F., Grant, A. L., Hogan, R. J., Belcher, S. E., Thomson, D. J., Devenish, B. J., Marenco, F., Hort, M. C., Haywood, J. M., Ansmann, A., Mattis, I., and Clarisse, L.: Evaluating the structure and magnitude of the ash plume during the initial phase of the 2010 Eyjafjallajökull eruption using lidar observations and NAME simulations, J. Geophys. Res.-Atmos., 116, D00U03, https://doi.org/10.1029/2011JD01560, 2011.

Eckhardt, S., Prata, A. J., Seibert, P., Stebel, K., and Stohl, A.: Estimation of the vertical profile of sulfur dioxide injection into the atmosphere by a volcanic eruption using satellite column measurements and inverse transport modeling, Atmos. Chem. Phys., 8, 3881-3897, https://doi.org/10.5194/acp-8-3881-2008, 2008.

EMEP Status Report 1/2016: Transboundary particulate matter, photo-axidants, acidifying and eutrophying components, EMEP MSC-W \& CCC \& CEIP, Norwegian Meteorlogical Institute (EMEP MSC-W), Oslo, Norway, 2016.

European Commission: Volcano Grimsvötn: how is the European response different to the Eyjafjallajökull eruption last year? Frequently Asked Questions, available at: http://europa.eu/rapid/ press-release_MEMO-11-346_en.htm, 2011.

Francis, P. N., Cooke, M. C., and Saunders, R.W.: Retrieval of physical properties of volcanic ash using Meteosat: A case study from the 2010 Eyjafjallajökull eruption, J. Geophys. Res.-Atmos., 117, D00U09, https://doi.org/10.1029/2011JD016788, 2012.

Gudmundsson, M. T., Thordarson, T., Höskuldsson, Á., Larsen, G., Björnsson, H., Prata, F. J., Oddsson, B., Magnusson, E., Högnsdottir, T., Petersen, G. N., Hayward, C. L., Stevenson, J. A., and Jonsdottir, I: Ash generation and distribution from the AprilMay 2010 eruption of Eyjafjallajökull, Iceland, Scientific Reports, 2, 572, https://doi.org/10.1038/srep00572, 2012.

Jordan, C., Sigmundsson, F., Vogfjord, K., Gudmundsson, M. T., Kristinsson, I., Loughlin, S., Ilyinskaya, E., Hooper, A., Kylling, A,. Witham, C., Bean, C., Braiden, A., Ripepe, M., and Prata, F.: Futurevolc: a European volcanological supersite observatory in Iceland, a monitoring system and network for the future. In: IEEE International Geoscience and Remote Sensing Symposium 2013, Melbourne, Australia, 21-26 July 2013, 286-289, 2013.

Kylling, A., Kahnert, M., Lindqvist, H., and Nousiainen, T.: Volcanic ash infrared signature: porous non-spherical ash particle shapes compared to homogeneous spherical ash particles, Atmos. Meas. Tech., 7, 919-929, https://doi.org/10.5194/amt-7919-2014, 2014.

Kylling, A., Kristiansen, N., Stohl, A., Buras-Schnell, R., Emde, C., and Gasteiger, J.: A model sensitivity study of the impact of clouds on satellite detection and retrieval of volcanic ash, Atmos. Meas. Tech., 8, 1935-1949, https://doi.org/10.5194/amt-8-19352015, 2015.

Kristiansen, N. I., Stohl, A., Prata, A. J., Richter, A., Eckhardt, S., Seibert, P., Hoffmann, A., Ritter, C., Bitar, L., Duck, T. J., and Stebel K. Remote sensing and inverse transport modeling of the Kasatochi eruption sulfur dioxide cloud, J. Geophys. Res., 115, D00L16, https://doi.org/10.1029/2009JD013286, 2010.

Kristiansen, N. I., A. Stohl, Prata, A. J., Bukowiecki, N., Dacre, H., Eckhardt, S., Henne, S., Hort, M. C., Johnson, B. T., Marenco, F., Neininger, B., Reitebuch, O., Seibert, P., Thomson, D. J., Webster, H. N., and Weinzierl, B.: Performance assessment of a volcanic ash transport model mini-ensemble used for inverse modeling of the 2010 Eyjafjallajökull eruption, J. Geophys. Res.Atmos. 117, D00U11, https://doi.org/10.1029/2011JD016844, 2012.

Kristiansen, N. I., Prata, A. J., Stohl, A., and Carn, S. A.: Stratospheric volcanic ash emissions from the 13 February 2014 Kelut eruption, Geophys. Res. Lett., 42, 588-596, https://doi.org/10.1002/2014GL062307, 2015.

Mastin, L. G., Guffanti, M., Servranckx, R., Webley, P., Barsotti, S., Dean, K., Durant, A., Ewert, J. W., Neri, A., Rose, W. I., Schneider, D., Siebert, L., Stunder, B., Swanson, G., Tupper, A., Volentik, A., and Waythomas, C. F.: A multidisciplinary effort to assign realistic source parameters to models of volcanic ash-cloud transport and dispersion during eruptions, J. Volcanol. Geoth. Res., 186, 10-21, 2009.

Moxnes, E. D., Kristiansen, N. I., Stohl, A., Clarisse, L., Durant, A., Weber, K., and Vogel, A.: Separation of ash and sulfur dioxide during the 2011 Grímsvötn eruption, J. Geophys. Res.-Atmos., 119, 7477-7501, https://doi.org/10.1002/2013JD021129, 2014.

Pappalardo, G., Mona, L., D’Amico, G., Wandinger, U., Adam, M., Amodeo, A., Ansmann, A., Apituley, A., Alados Arboledas, L., Balis, D., Boselli, A., Bravo-Aranda, J. A., Chaikovsky, A., Comeron, A., Cuesta, J., De Tomasi, F., Freudenthaler, V., Gausa, M., Giannakaki, E., Giehl, H., Giunta, A., Grigorov, I., Groß, S., Haeffelin, M., Hiebsch, A., Iarlori, M., Lange, D., Linné, H., Madonna, F., Mattis, I., Mamouri, R.-E., McAuliffe, M. A. P., Mitev, V., Molero, F., Navas-Guzman, F., Nicolae, D., Papayannis, A., Perrone, M. R., Pietras, C., Pietruczuk, A., Pisani, G., Preißler, J., Pujadas, M., Rizi, V., Ruth, A. A., Schmidt, J., Schnell, F., Seifert, P., Serikov, I., Sicard, M., Simeonov, V., Spinelli, N., Stebel, K., Tesche, M., Trickl, T., Wang, X., Wagner, F., Wiegner, M., and Wilson, K. M.: Four-dimensional distribution of the 2010 Eyjafjallajökull volcanic cloud over Europe observed by EARLINET, Atmos. Chem. Phys., 13, 4429-4450, https://doi.org/10.5194/acp-13-4429-2013, 2013.

Pollack, J. B., Toon, O. B., and Khare, B. N.: Optical properties of some terrestrial rocks and glasses, Icarus, 19, 372-389, https://doi.org/10.1016/0019-1035(73)90115-2, 1973.

Prata, A. J.: Observations of volcanic ash clouds in the $10-12 \mu \mathrm{m}$ window using AVHRR/2 data, Int. J. Remote Sens., 10, 751-761, 1989.

Prata, A. J. and Prata, A. T.: Eyjafjallajökull volcanic ash concentrations determined using Spin Enhanced Visible and Infrared Imager measurements, J. Geophys. Res., 117, D00U23, https://doi.org/10.1029/2011JD016800, 2012. 
Schmetz, J., Pili, P., Tjemkes, S., and Just, D.: An introduction to Meteosat second generation (MSG), B. Am. Meteorol. Soc., 83, 977-992, 2002.

Seibert, P.: Inverse modelling of sulfur emissions in Europe based on trajectories, in: Inverse Methods in Global Biogeochemical Cycles, edited by: Kasibhatla, P., Heimann, M., Rayner, P., Mahowald, N., Prinn, R. G., and Hartley, D. E., Geophysical Monograph 114, American Geophysical Union, ISBN 0-87590-097-6, Washington, DC, USA, 147-154, 2000.

Simpson, D., Benedictow, A., Berge, H., Bergström, R., Emberson, L. D., Fagerli, H., Flechard, C. R., Hayman, G. D., Gauss, M., Jonson, J. E., Jenkin, M. E., Nyíri, A., Richter, C., Semeena, V. S., Tsyro, S., Tuovinen, J.-P., Valdebenito, Á., and Wind, P.: The EMEP MSC-W chemical transport model - technical description, Atmos. Chem. Phys., 12, 7825-7865, https://doi.org/10.5194/acp-12-7825-2012, 2012.

Steensen, B. M., Schulz, M., Wind, P., Valdebenito, Á. M., and Fagerli, H.: The operational eEMEP model version 10.4 for volcanic $\mathrm{SO}_{2}$ and ash forecasting, Geosci. Model Dev., 10, 19271943, https://doi.org/10.5194/gmd-10-1927-2017, 2017.

Stohl, A., Prata, A. J., Eckhardt, S., Clarisse, L., Durant, A., Henne, S., Kristiansen, N. I., Minikin, A., Schumann, U., Seibert, P., Stebel, K., Thomas, H. E., Thorsteinsson, T., Tørseth, K., and Weinzierl, B.: Determination of time- and height-resolved volcanic ash emissions and their use for quantitative ash dispersion modeling: the 2010 Eyjafjallajökull eruption, Atmos. Chem. Phys., 11, 4333-4351, https://doi.org/10.5194/acp-114333-2011, 2011.
Volz, F. E.: Infrared optical constants of ammonium sulfate, Sahara dust, volcanic pumice, and flyash, Appl. Optics, 12, 564-568, 1973

Wen, S. and Rose, W. I.: Retrieval of sizes and total masses of particles in volcanic clouds using AVHRR bands 4 and 5, J. Geophys. Res., 99, 5421-5431, 1994.

Wernli, H., Paulat, M., Hagen, M., and Frei, C.: SAL-A novel quality measure for the verification of quantitative precipitation forecasts, Mon. Weather Rev., 136, 4470-4487, 2008.

Wilkins, K. L., Watson, I. M., Kristiansen, N. I., Webster, H. N., Thomson, D. J., Dacre, H. F., and Prata, A. J.: Using data insertion with the NAME model to simulate the 8 May 2010 Eyjafjallajökull volcanic ash cloud, J. Geophys. Res.-Atmos., 121, 306-323, 2016a.

Wilkins, K. L., Western, L. M., and Watson, I. M.: Simulating atmospheric transport of the 2011 Grímsvötn ash cloud using a data insertion update scheme, Atmos. Environ., 141, 48-59, $2016 \mathrm{~b}$.

Winker, D. M., Liu, Z., Omar, A., Tackett, J., and Fairlie, D.: CALIOP observations of the transport of ash from the Eyjafjallajökull volcano in April 2010, J. Geophys. Res., 117, D00U15, https://doi.org/10.1029/2011JD016499, 2012.

Yu, T., Rose, W. I., and Prata, A. J.: Atmospheric correction for satellite-based volcanic ash mapping and retrievals using "split window" IR data from GOES and AVHRR, J. Geophys. Res.Atmos., 107, https://doi.org/10.1029/2001JD000706, 2002. 